\title{
COMBINED 3D BUILDING SURVEYING TECHNIQUES - TERRESTRIAL LASER SCANNING (TLS) AND TOTAL STATION SURVEYING FOR BIM DATA MANAGEMENT PURPOSES
}

\author{
Tarvo MILL ${ }^{\mathrm{a}}$, Aivars ALT $^{\mathrm{b}}$, Roode LIIAS ${ }^{\mathrm{a}}$ \\ ${ }^{a}$ Department of Construction Geodesy, Tallinn University of Technology, Ehitajate tee 5, 19086 Tallinn, \\ Estonia \\ ${ }^{b}$ Department of Civil Engineering, Tallinn University of Applied Sciences, Pärnu mnt 62, 10135 Tallinn, \\ Estonia
}

Received 23 Dec 2012; accepted 8 Apr 2013

\begin{abstract}
Building information modelling (BIM) represents the process of development and use of a computer generated model to simulate the planning, design, construction and operation of a building. The utilisation of building information models has increased in recent years due to their economic benefits in design and construction phases and in building management. BIM has been widely applied in the design and construction of new buildings but rarely in the management of existing ones. The point of creating a BIM model for an existing building is to produce accurate information related to the building, including its physical and functional characteristics, geometry and inner spatial relationships. The case study provides a critical appraisal of the process of both collecting accurate survey data using a terrestrial laser scanner combined with a total station and creating a BIM model as the basis of a digital management model. The case study shows that it is possible to detect and define facade damage by integration of the laser scanning point cloud and the creation of the BIM model. The paper will also give an overview of terrestrial laser scanning (TLS), total station surveying, geodetic survey networks and data processing to create a BIM model.
\end{abstract}

Keywords: terrestrial laser scanning, total station surveying, BIM, building managing.

Reference to this paper should be made as follows: Mill, T.; Alt, A.; Liias, R. 2013. Combined 3D building surveying techniques - terrestrial laser scanning (TLS) and total station surveying for BIM data management purposes, Journal of Civil Engineering and Management 19(Supplement 1): S23-S32.

http://dx.doi.org/10.3846/13923730.2013.795187

\section{Introduction}

Building renovation is a growing trend in the construction sector. The amount and granularity of information needed for renovation design is growing in tandem with the fields of architecture, construction, engineering and building management. We should not overlook the importance of cost efficiency. In order to design cost- efficient renovation works, it is important to have at hand accurate data reflecting the existing situation. This will ultimately be the basis of all design processes and can affect the allocation of costs.

Several studies on the creation of 3D models of existing buildings have been conducted over the last decades. These 3D models have been of great importance to architectural city planning. For example, Donath and Thurow (2007) have suggested an integrated building information system, combined with a digitally supported survey solution for architectural surveying. The study brings out a number of problem areas mainly concerned with accuracies in presenting building geometry.

Laser scanning with its high level of accuracy and high level of detail is very versatile and has been utilised, for example in the assessment of buildings' condition (Tang, Akinci 2012) and computing accurate parametric models of complex objects (Bauer, Polthier 2009). For example, Haala and Kada (2010) have focused their study on the creation of 3D models of buildings' roofs and facades using 3D terrestrial laser scanning (TLS) data, although Rajala and Penttilä (2006) and Larsen et al. (2011) point out that digitalising a building using TLS data entails a high volume of work. In the last few years, point cloud software development has increased the efficiency of point cloud processing and made it more flexible when creating building information modelling (BIM) models. Bosché (2010) has pointed out how geometry created with accurate survey (information-rich) data is related to the

Corresponding author: Tarvo Mill

E-mail: tarvo@tktk.ee 
BIM model. Using BIM technology requires in addition to geometric information, other data, such as physical, structural and functional parameters.

The present case study went through the following stages: establishing the external and internal geodetic survey networks, planning and conducting laser scanning of the external part of the building, planning and conducting a total station survey of the internal part of the building. At the end of each stage, data processing was performed, and finally a BIM model was generated.

An unexpected and positive outcome of the case study was the possibility to detect and define facade damage by integration of the laser scanning point cloud and the BIM model created.

\section{The case study object}

The case study object was the main building of the Tallinna Tehnikakõrgkool/University of Applied Sciences (TTK/UAS) located in the capital city of Estonia. The building, built in the 1950s, was designed and built by the Leningrad architectural institute Giprošaht architect H. Serlin from 1946 to 1953. The building is in the stalinistic style, characterised by an abundance of ornaments.

Over the years, the building has been renovated and expanded numerous times. Since few of the original architectural drawings are extant, the daily administrative work has been carried out using hardcopy $2 \mathrm{D}$ inventory plans, some of which were made in 1975. The main problem with inventory plans is that often they do not coincide with reality. The situation is similar for existing buildings in Estonia.

In order to simplify the process of administration and planning, it is essential to have reliable and informative spatial data. In this case, the existing data was not sufficient enough to carry out any administrative activity. As a result, a building survey was necessary, either as an extension or validation of existing building documentation or to provide new documentation (Donath, Thurow 2007).

The current state-of-the-art approach to collecting, organising and integrating survey data of an existing building into a single data structure is to model it using BIM tools (Eastman 2008).

\section{Concept of BIM}

BIM represents the process of development and use of a computer generated model to simulate the planning, design, construction and operation of a building. The resulting model, a building information model, is a data-rich, object-oriented, intelligent and parametric digital representation of the building, from which views and data appropriate to various users' needs can be extracted and analysed to generate information that can be used to make decisions and to improve the process of delivering the building (Azhar 2011). In order to simplify real-time tracking of projects and information management, the processes can be integrated with different applications like Radio Frequency Identification (RFID) and Geographic Information System (GIS) (Cheng et al. 2008). When combining RFID, GIS and BIM, we gain a novel and effective tool with wide application in the Architectural, Engineering and Construction (AEC) industry.

The basic parameters describing vector objects are shape and volume and can be simply expressed as coordinate points and their orientation as an angular value within a $3 \mathrm{D}$ space. Specifications for the materials and texture can accompany the numerical data. Parametric CAD differs from generic 3D CAD in that parameters are assigned to an object prior to its use. The $3 \mathrm{D}$ object as a parametric model can be edited to revise any or all of its parameters of construction, texture and orientation (CSA 2005).

Architectural CAD has been developed from 2D graphic computer representation to parametric modelling to 3D modelling (Tse et al. 2005), and on to feature extraction and finally to BIM.

The leading BIM software platforms are Autodesk Revit, GraphiSoft ArchiCAD and Bentley Architecture. ArchiCAD by Graphisoft (2012) is an architectural design application built around the BIM concept as a standalone application. In ArchiCAD the modelling of objects can be achieved using standard parametric construction elements. These elements are embedded in the software (such as walls, columns, beams, slabs, roofs, etc.) or created as new objects using the embedded scripting language Geometric Descriptive Language (GDL). The use of GDL allows the creation of any number of rich parametric BIM objects and for their storage in internal libraries or data bases for further reuse or modification (Tse et al. 2005). Revit (Autodesk Inc. 2012) is also a BIM platform, where the user constructs a mass model with a combination of solid forms and void forms. The faces of the mass volume can be turned into building elements, floors and other architectural elements can be generated inside the mass model. Bentley Architecture's interface is completely different from that of other types of BIM software, in the sense that it is not a standalone application but is a plug-in for Bentley MicroStation TriForma, which in turn is also a plug-in for the fundamental Bentley MicroStation (Tse et al. 2005).

\section{Review of technology}

This section gives an overview of the application of two different techniques to acquire accurate geometric information for a building. Traditionally, a total station is used to record single points. Using a total station, however, is relatively time-consuming since points are recorded one by one. Each survey point describes building edges or points of interest. This 
method does not allow the possibility to acquire complex surface structures. In the case of TLS, one scan results in a large quantity of points in a systematic pattern, also called a point cloud. Many different TLS systems are on the market for a wide variety of object sizes, ranges and accuracies. In response to total station survey and TLS, close-range stereo photogrammetry is the predominant method for geometric documentation of a complex consisting of heritage objects. The close-range stereo photogrammetric measurement system consists mainly of a digital camera, a laser distance metre, and a special support for two devices (Ordóñez et al. 2010). A more detailed overview of close-range photogrammetry applications is given by Ordóñez et al. (2010) and Jiang et al. (2008). Boehler and Marbs (2004) give a comparison of TLS and close-range photogrammetry.

\subsection{TLS technology}

A terrestrial laser scanner scans its entire field of view one point at a time by changing the laser rangefinder's direction of view to scan different points (Mill et al. 2011). According to scanning technology, terrestrial laser scanners can be divided into three basic groups: triangulation, time of flight (TOF) and phase-shift (PS) or phase-based (PB).

Triangulation laser scanners shine a laser pattern onto the object and use a camera to look for the location of the laser's projection onto the object (Lerma et al. 2010). The pattern projector and the object being measured are configured in a triangle, hence the name triangulation scanner. Triangulation laser scanners are used in applications generally requiring an operating range that is less than $25 \mathrm{~m}$ (Mensi 2012). TOF laser scanners compute distances by measuring the time frame between sending a short laser pulse and receiving its reflection from an object. Since the laser pulse travels with a constant speed, the speed of light, the distance between the scanner and the object can be determined. TOF laser scanners can determine up to 50,000 points per second up to a distance of over $1 \mathrm{~km}$ from the scanner (Riegl Laser Measurement Systems GmbH 2011).

PB laser scanners avoid using high precision clocks by modulating the power of the laser beam. The emitted (incoherent) light is modulated in amplitude and fired onto a surface. The scattered reflection is collected and a circuit measures the phase difference between the sent and received wave-forms, hence a time delay. This method allows faster measuring, up to 1,000,000 points/s (Zoller + Fröhlich GmbH 2012). Because of the laser power required to modulate the beam to certain frequencies, the range of these scanners are limited to approximately between 25 and $80 \mathrm{~m}$ (3D Risk Mapping 2008).

Laser scanning technology possesses many capabilities for gathering data, but certain aspects should be considered when planning recording tasks. Laser scanning does not provide unlimited geometric accuracy. Scanning accuracy is dependent on the surface material and reflecting capabilities of objects observed. A thorough analysis of laser scanning accuracy has been carried out by Boehler and Marbs (2003), Schulz and Ingesand (2004), Mechelke et al. (2007) and Alkan and Karsidag (2012).

\subsection{Total station survey technology}

Total stations combine electronic theodolites and EDM into a single unit. They digitally observe and record horizontal directions, vertical directions, and slope distances. These digital data observations can be adjusted and transformed to local $x-y-z$ coordinates using an internal or external microprocessor. Various atmospheric corrections, grid and geodetic corrections, and elevation factors can also be entered and applied. The total station may internally perform and save the observations, or (more commonly) these data may be downloaded to an external data collector. With the addition of a data collector, the total station interfaces directly with onboard microprocessors, external PCs, and software (US Army Corps of Engineers 2007). Total stations can electronically encode angles to 1 arc-second with accuracy down to 0.5 arc-second. Distances can be measured with accuracy down to $0.5 \mathrm{~mm}$ (Leica Geosystems AG 2012a).

\section{The case study}

\subsection{Workflow}

The case study workflow chart is laid out in Figure 1. The workflow chart depicts in detail the stages of the case study. The workflow is divided into five parts.

\subsection{Establishment of a geodetic network}

The initial phase of the survey project involved establishing a geodetic survey network around the

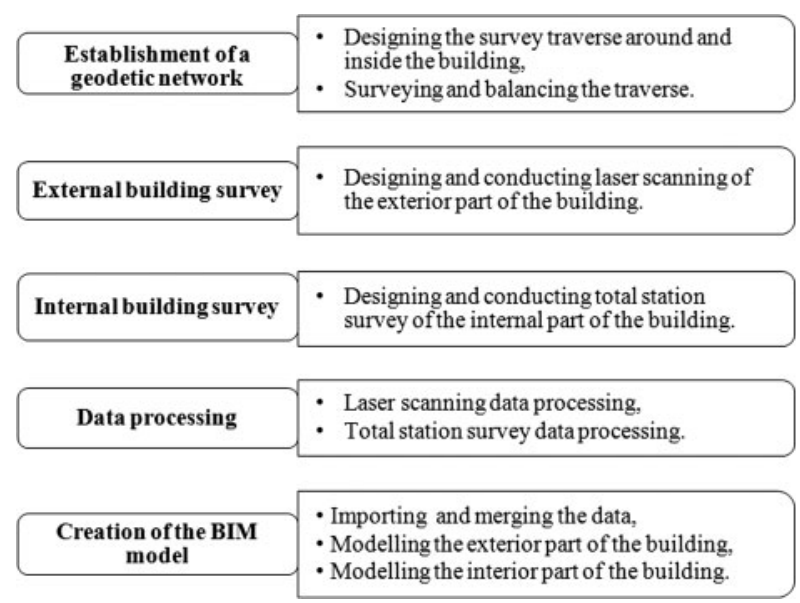

Fig. 1. Workflow of the stages of the case study 


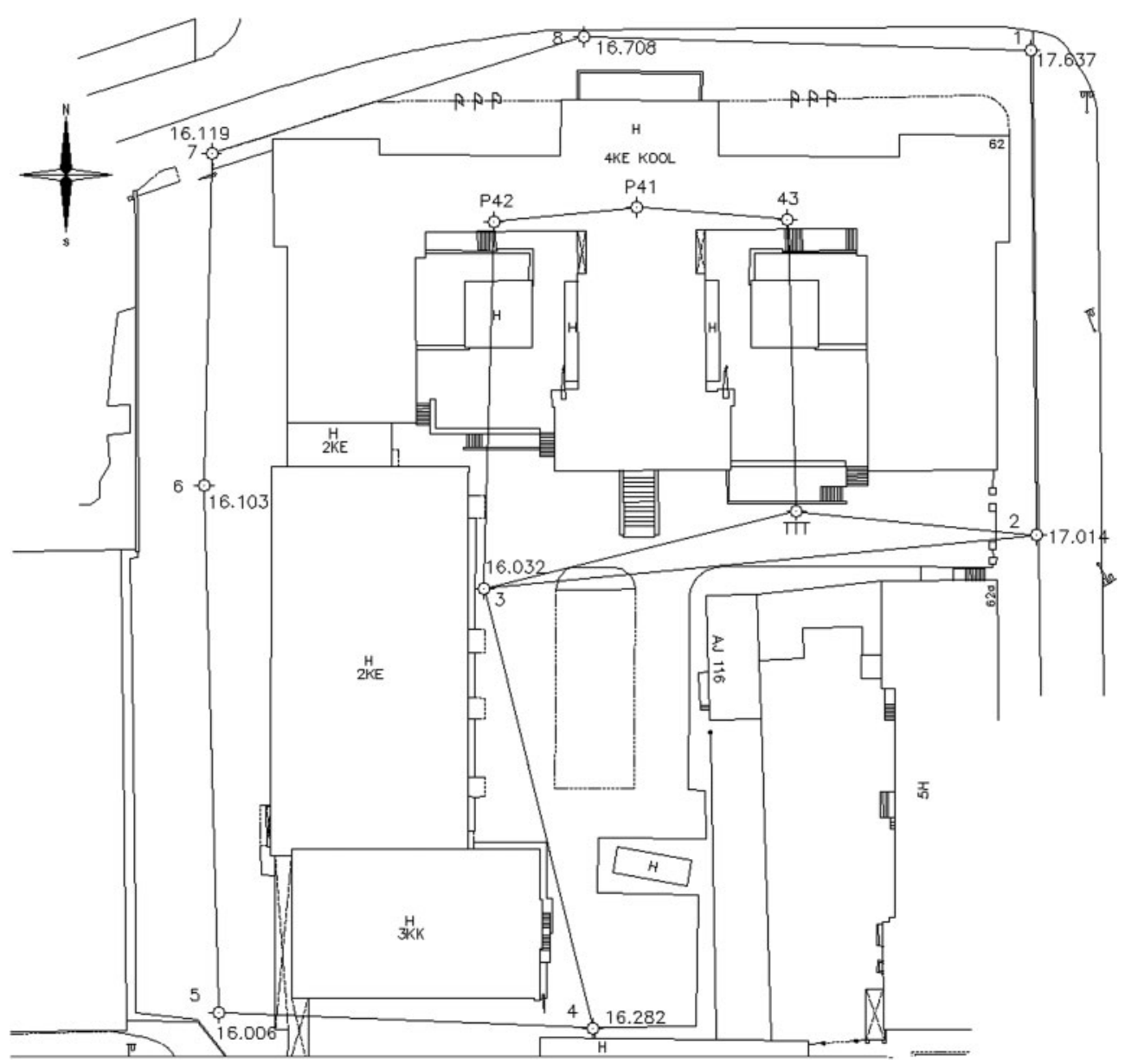

Fig. 2. Established survey traverses

building to provide a common reference frame and to ensure survey data compatibility. Survey points around the building (Fig. 2) in the closed survey traverse were determined using total station measurements. The closed traverse was adjusted, using Trimble M3 Controller software, which uses the Compass adjustment also known as the Bowditch adjustment. The Compass adjustment distributes the error in proportion to the length of the traverse lines (Muskett 1995).

An additional four survey traverses inside the building, one on each floor connected to baselines outside the building were generated (see Fig. 2, survey points on the fourth floor P42, P41, P43).

The heights of the external traverse points were levelled separately using a digital level Leica Sprinter 100.

\subsection{External building survey}

The external building survey was conducted using a TOF terrestrial laser scanner Leica C10 in September 2011. The maximum range of the device is $300 \mathrm{~m}$ with a $360 \times 270^{\circ}$ field of view and maximum scanning rate of up to 50,000 points/sec (Leica Geosystems AG 2012b).
TLS data was acquired at 26 stations, to receive information from as many parts of the object as possible and to leave fewer hidden sections. Such a dense database of the facade will allow the Administrative board to assess the extent of damaged surface area and other facade elements. In total, over 223 million points were recorded from approximately $9545 \mathrm{~m}^{2}$ of facade area $(415 \mathrm{~m}$ perimeter, $23 \mathrm{~m}$ in height) and from $2924 \mathrm{~m}^{2}$ of roof area, each point consisting of $x, y, z$ and intensity values (Fig. 3). To obtain a complete representation of the scanned object, the scans were combined into one dataset by directly georeferencing the point clouds into the predetermined geodetic reference frame.

\subsection{Internal building survey}

Since the level of interior detail was not high, the internal survey was accomplished using a total station Trimble M3. The total station was coordinated in each room using the internal survey traverses on each floor. As a result, all of the internal surveys were in a uniform system. The room perimeter was surveyed using the reflectorless measurement technique at a height of approximately $1 \mathrm{~m}$. The heights of ceilings, door lintels and windows, as well as the widths of 


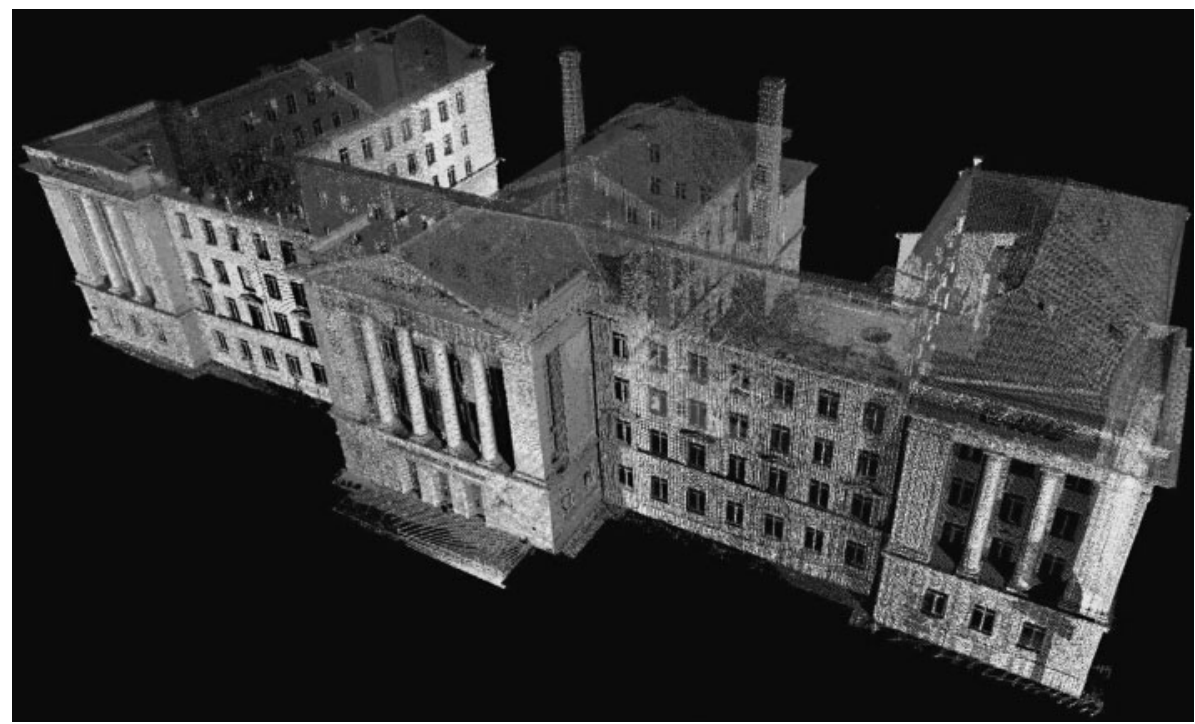

Fig. 3. The point cloud of the entire building in Leica Cyclone 7.1

windows, were sometimes measured using an electronic distance metre (Leica Disto A2) depending on the visibility inside the room. Since it was difficult to survey corners accurately, some of the corner positions were created during data processing using the extensions of the walls, where walls intersected.

\subsection{Data processing}

Data processing was divided into three different phases, the first, exterior point cloud processing, the second, internal total station survey data processing and the third, processing data using BIM software the BIM model of the building was created.

\subsubsection{Laser scanning data processing}

After the external perimeter of the building was laser scanned, information outside the object of interest was removed from the point cloud using Leica Cyclon 7.3 software. The data was saved in a *pts format for further processing in Autodesk Revit Structure 2013.

\subsubsection{Total station survey data processing}

Total station survey data processing was done using Autodesk AutoCAD 2011. First, 2D floor plans at zero height were created. Using the heights of ceilings in rooms, walls were created and since the perimeter was now known, door and window openings were added. Rooms were now simple 3D blocks in the correct plane position. These blocks were then merged onto the correct height of the floor in the $3 \mathrm{D}$ building model, as illustrated in Figure 4.

\subsection{Creation of the BIM model}

\subsubsection{Importing and merging the data}

The BIM model was created in Revit Structure 2013. Revit Structure 2013 was chosen, because it allows direct import of a point cloud data in common

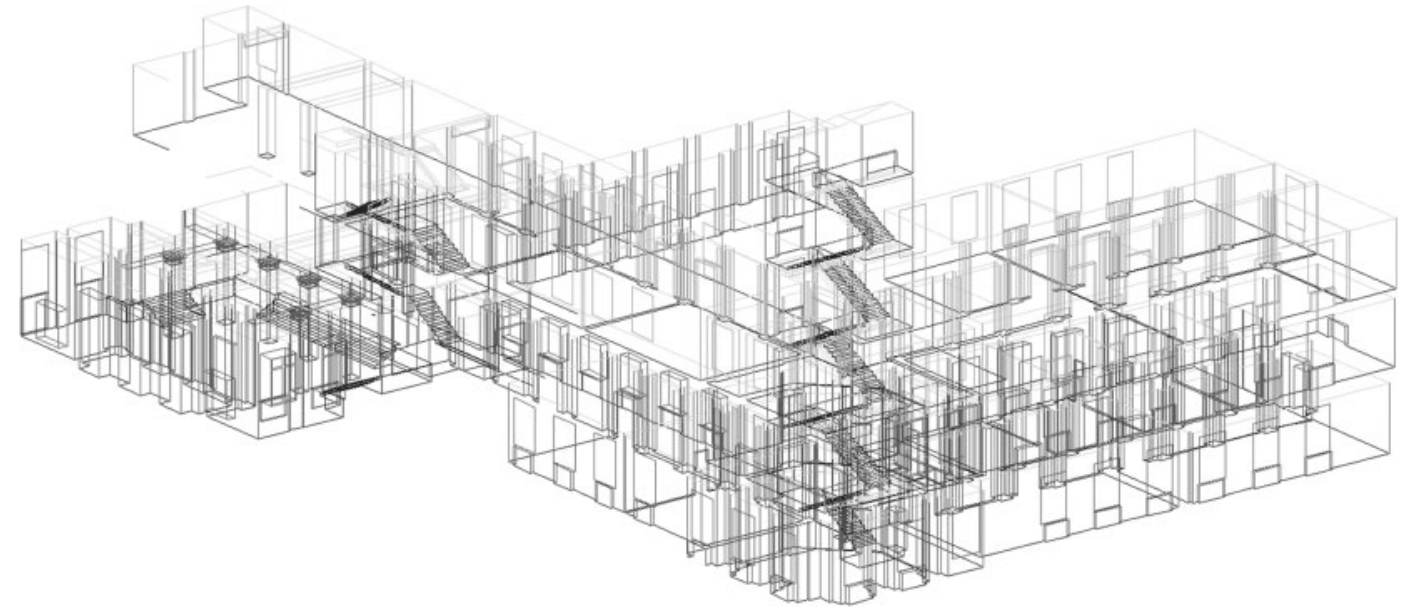

Fig. 4. A fragment of the 3D model of the building in AutoCAD 2011 


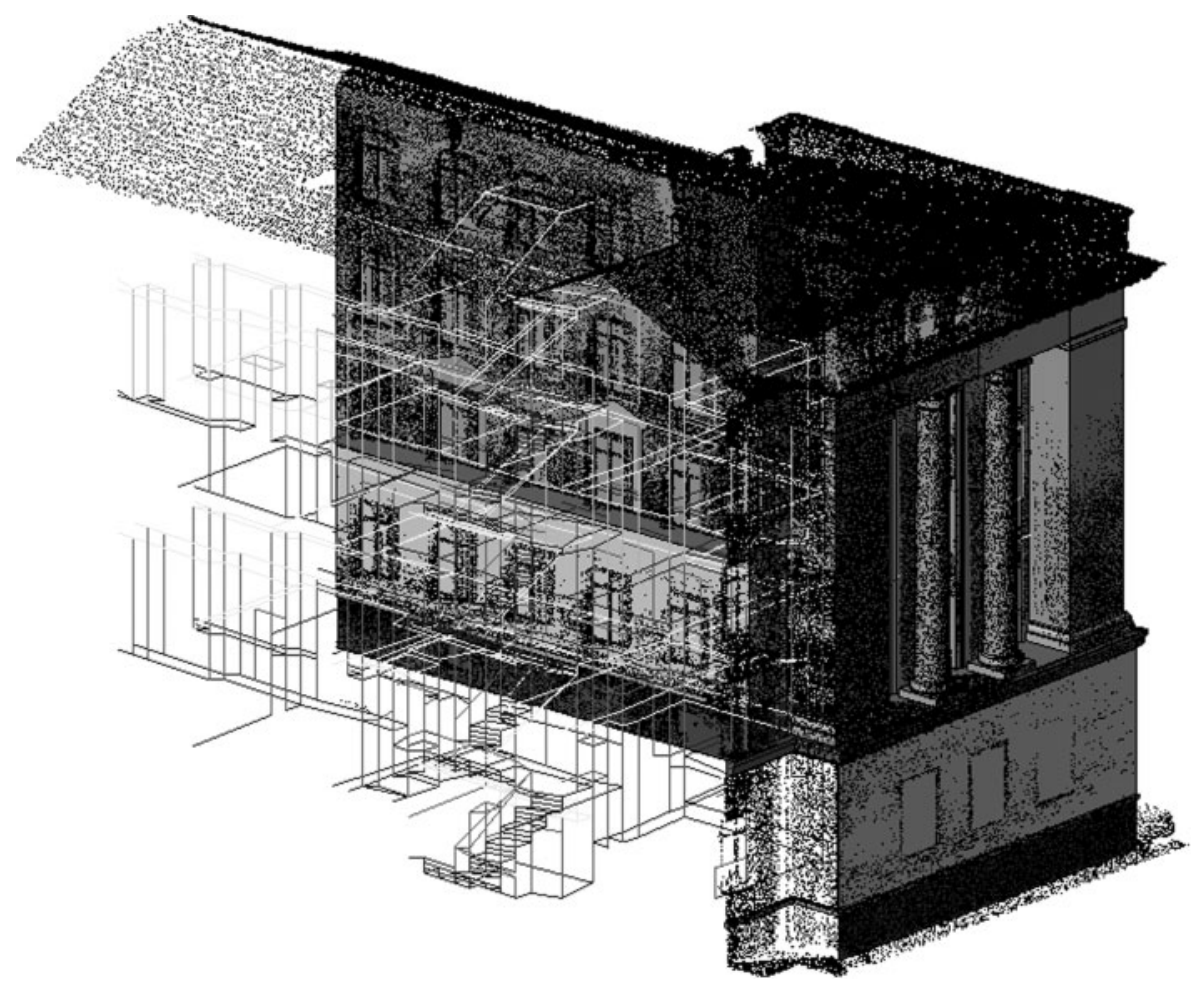

Fig. 5. A sample of the internal 3D model merged with the exterior point cloud

formats like *pts. The software uses a native *pcg format, and it is possible to convert the *pts format to the *pcg format.

Of equal importance is the possibility to export models in open formats like XML, IFC and DWF. The availability of open file formats can facilitate collaboration in data collecting, data processing and data application. It is worth noting that applications used for viewing, commenting and coordination are based on open file formats.

Since the building was surveyed using two different survey methods to create a model of the whole building, the internal AutoCAD 3D model based on the total station survey and the exterior laser scanning point cloud data (Fig. 5) had to be merged.

\subsubsection{Modelling the exterior}

The surface of the facade was modelled entirely using the laser scanning point cloud data. Since Revit Structure does not have an algorithm for determining the best fit for the location of the surface of the facade, the modeller chose the location manually. Choosing the right place for the surface manually may turn out to be very difficult, especially if the surface is rough and uneven (see Fig. 6).

The merged dataset is also used for marking the floor heights and axes of the building in Revit (Fig. 7).

Using Revit's commands like columns, walls, slabs, etc. different structural and architectural parts of the building were created. The procedure described above was used to build up the rest of the model.

\subsubsection{Modelling the interior}

The taxonomy of the BIM is as follows: the model is divided into separate floors and each floor is divided into building sections according to its logical location.

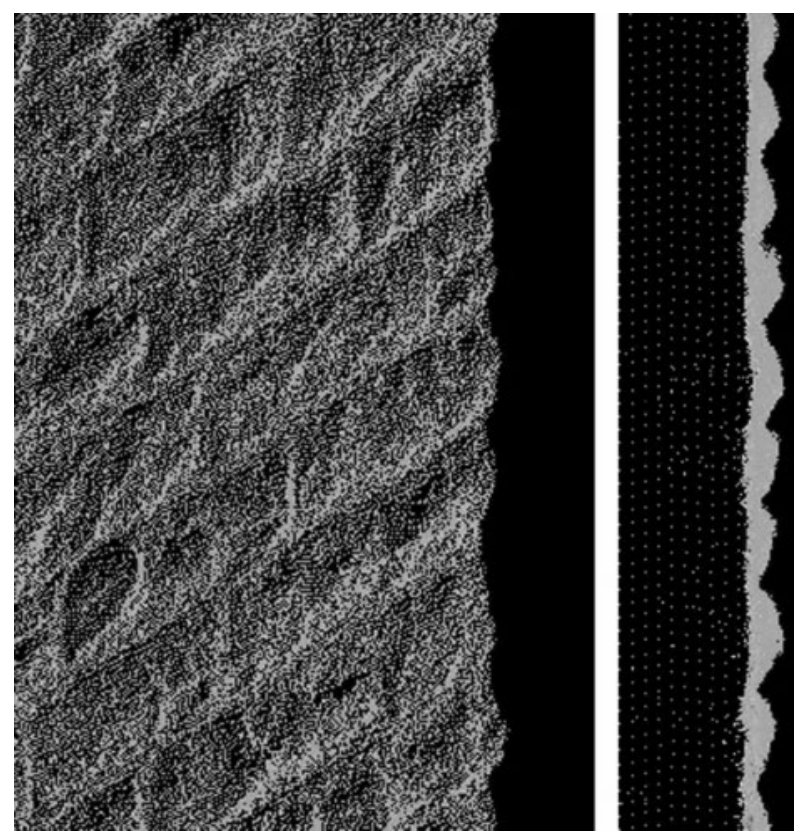

Fig. 6. A sample of the building's limestone facade, front view (left) side view (right) 


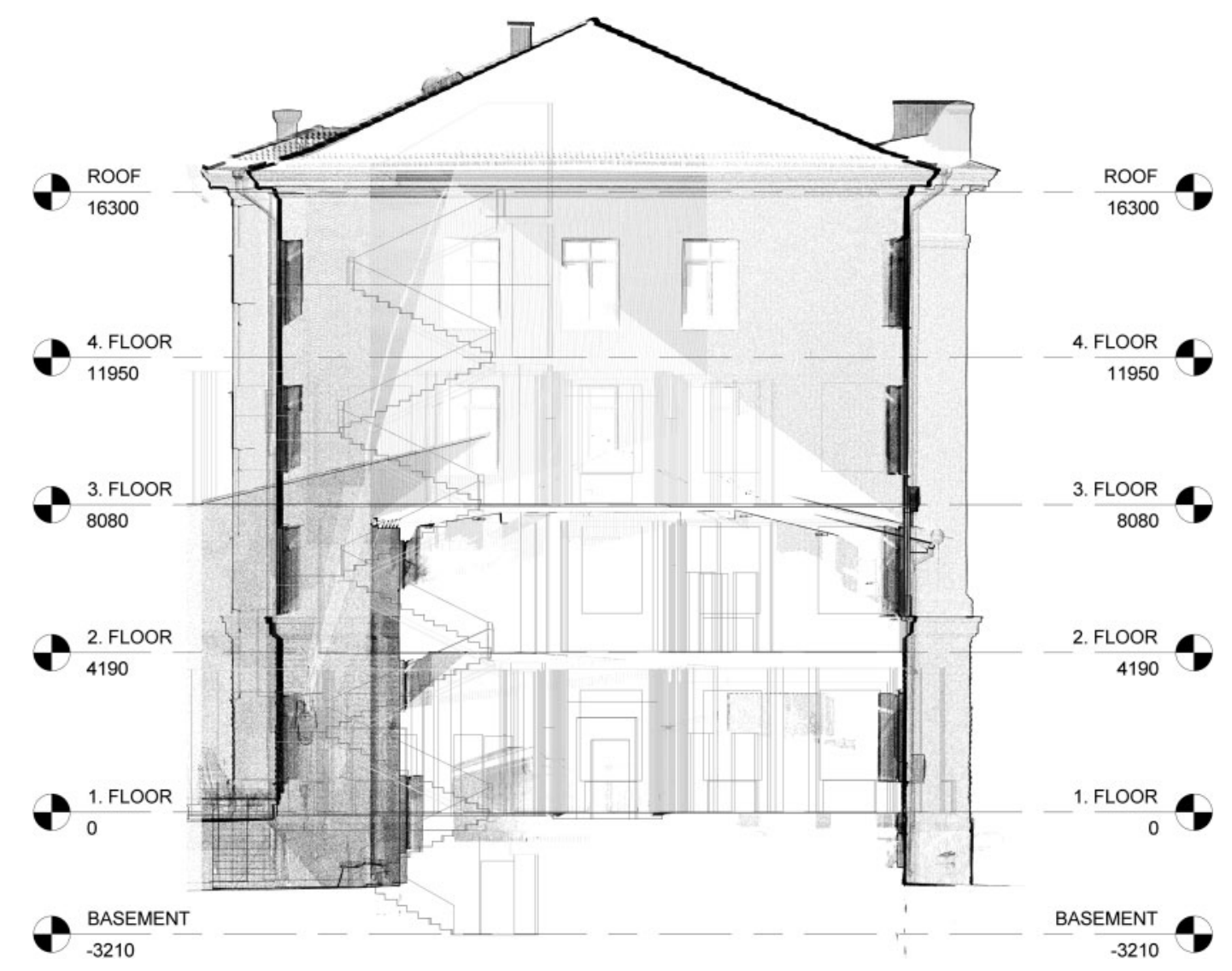

Fig. 7. Combined point cloud data with AutoCAD 3D to fit height marks

The taxonomy was designed according to the principle that it would be possible to display smaller parts of the whole BIM model separately, in turn making it more convenient for the user to work with a specific section or floor. Such an approach would also put less of a load on the computer hardware. Another reason for using smaller sections is that renovation is typically carried out on one room or floor at a time, since the building is in continuous use. For example, renovation of the ventilation system is planned at first only for section A on the first floor. The taxonomy created by the model simplifies the designing for only that part of the ventilation system.

According to the American Institute of Architects (AIA), the level of detail of the model is 300 (Weygant 2011), meaning that the model shows the quantity, shape, size, location and orientation of elements. The inserted elements carry sufficient information concerning the required performance criteria; therefore, a detailed analysis of the construction elements can be performed. For example, a wall structure is modelled in sufficient detail enough to carry out a dynamic energy analysis. As a result, it is possible to simulate different insulation options for outside walls. It can also be checked if the planned ventilation system matches the user profiles of different rooms.

\section{The benefits of the creation of a BIM model}

Displaying the model created in Revit and the point cloud data simultaneously is an effective way to define the extent of facade damage. Using traditional survey methods to achieve such an objective would have been challenging. An example of facade plaster damage is shown in Figure 8. It is possible to measure the damaged area in the direction needed.

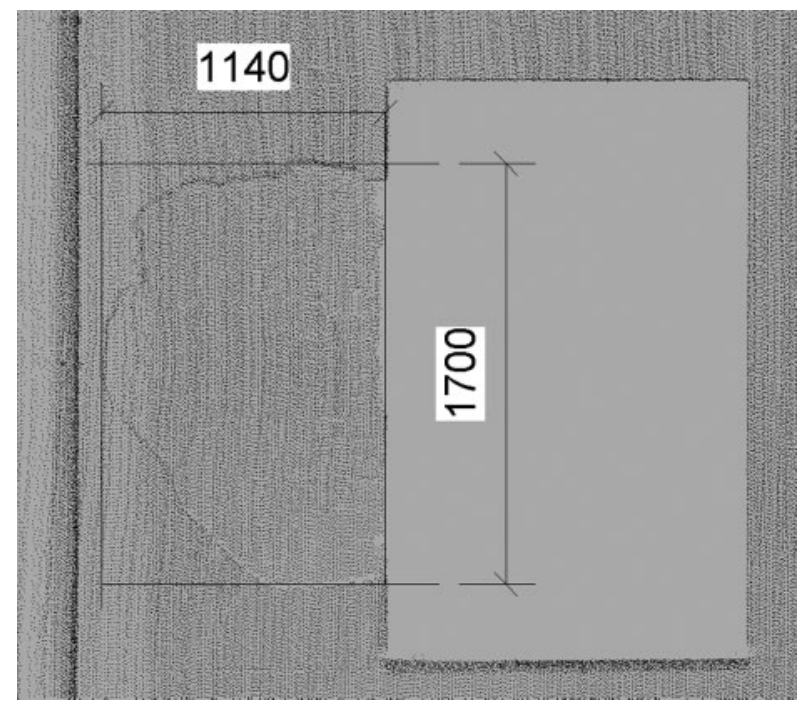

Fig. 8. The damaged facade area dimensions 

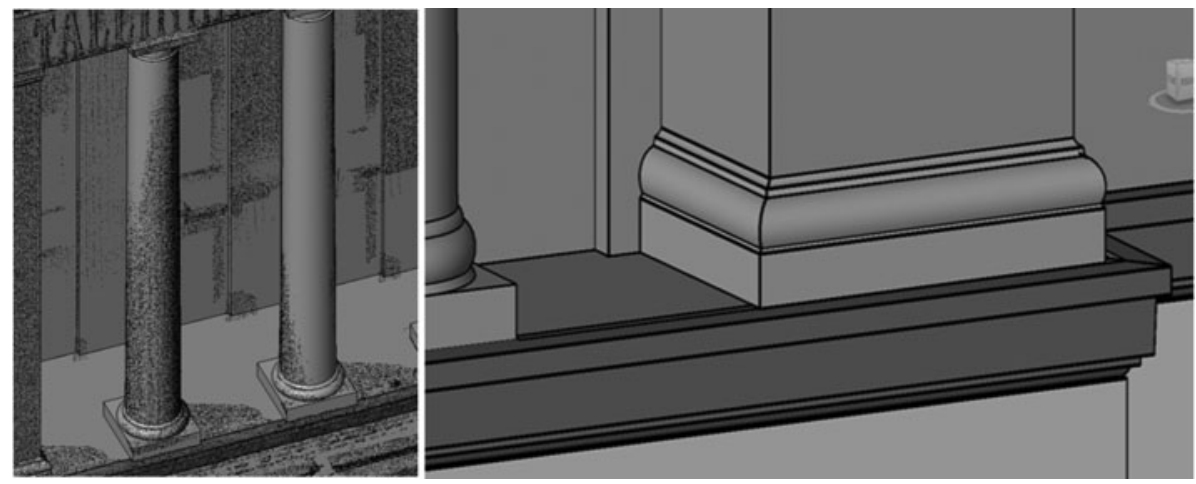

Fig. 9. Columns and ornaments

Tools developed to create models from a point cloud are effective and time saving when modelling complicated but geometrically proportional facade elements like columns or ornaments (Fig. 9). Such elements can be rendered with a high degree of accuracy.

An important benefit of a large amount of high accuracy data is the ability to detect discrepancies between the existing drawings and the real situation, in this case, in the point cloud. For example, in 2007, a new library was built in the courtyard. The library has a pyramid-shaped skylight. When the existing fire zone drawings were compared with the point cloud data, a major conflict was discovered concerning the skylight of the new library. The existing drawings and the point cloud data do not coincide, with differences up to $4000 \mathrm{~mm}$. The shape and the size of skylight are remarkably different. This issue leads to another challenge: different drawings containing the same information might be remarkably different. Fire section drawings of the building contain radically wrong information about the skylight, though the HVAC drawings present information in harmony with reality. This problem highlights the shortcomings in the management of building documentation.

\section{Problem areas}

The case study uncovered a series of problematic areas for future research and development that need to be resolved. The problem areas are covered in the following sections.

\subsection{Lack of flexibility when integrating different point cloud data}

Problems arose when trying to merge different sets of point cloud data since the software used does not support working in survey coordinate systems. The merging should be done in point cloud processing software. As a consequence, additional data processing and data editing is limited. In a situation where an additional laser scanning campaign is carried out, it would be difficult to merge the additional data with existing data and moreover to ensure the accuracy and quality of merged data. A simple solution would be to leave out the additional laser scanning campaign and design the process thoroughly. In practice, additional measurements are sometimes important and necessary.

\subsection{Absence of a best-fit algorithm}

A best-fit algorithm that could help the modeller create surfaces more easily is missing. At the moment a modeller has to choose the best-fit location of surfaces. This could result either in too much generalisation or too little generalisation in the produced model. Either way, modelling will take extra time, since the work has to be done manually.

\subsection{Creating window openings}

Creating window openings in cases where the opening is not shaped like a cuboid have to be done manually. Other difficulties arise if wall thicknesses differ significantly. Since there is no automatic reconditioning method for windows, this should be considered a significant shortcoming, especially when dealing with larger facilities. One solution to the problem would be to generalise the constructions and use a low level of detail.

\subsection{Missing standards for management applications}

Standards for building management applications determining requirements for data collection and the level of detail of object modelling are missing. At the moment a modeller can insert information into the model based on the direct needs of the manager rather than on the bases of standards. These direct needs usually reflect requirements of the specific situation and might not consider the information needed for the overall management system, which is connected with the building's lifecycle. 


\subsection{Organisational challenges}

Organisational challenges are related to the classifications under which the items are classified either based on EVS, TALO 200, Omniclass or Masterformat.

When a model is created for managing purposes, it is important that the information is unambiguous and accurate. A fundamental shortcoming is the lack of ability to uniquely describe building information models. The graphical information is one of many elements of a description of the inserted information, but when the data is processed and different databases are used, there is a need for unambiguous definitions. In the case of cross-border cooperation, there is a problem when combining different classifiers.

The problems identified require further research.

\section{Conclusions}

The case study presented the workflow and methodology for collecting and processing data for the purpose of creating a BIM model for data management purposes. The data collecting methodology combines the use of TLS with total station surveying. A complete description of the work carried out on the main building of the TTK University of Applied Sciences (TTK/UAS) is presented, and it includes the collecting of interior and exterior data, the data merging process and the creation of the BIM model. The case study highlights several benefits resulting from creation of a BIM model using a point cloud, such as the ability to detect and define the extent of facade damage. Problem areas concerning the process of composing the BIM model using different survey data were also pointed out. The case study shows that the surveying time, data processing time and level of detail are essential in the process of creating a BIM model of an existing building.

\section{References}

3D Risk Mapping. 2008. Theory and practice on terrestrial laser scanning [online]. University of Natural Resources and Life Sciences, Vienna [cited 5 November 2009]. Available from Internet:

https://irias.kuleuven.be/bitstream/123456789/201130/ 2/Leonardo_Tutorial_Final_vers5_ENGLISH.pdf

Alkan, R. M.; Karsidag, G. 2012. Analysis of the accuracy of terrestrial laser scanning measurements, in Proc. of the FIG Working Week, 6-10 May 2012, Rome, Italy, $16 \mathrm{p}$.

Autodesk Inc. 2012. Building information modeling [online], [cited 13 August 2012]. Available from Internet: http://usa.autodesk.com/building-information-modeling

Azhar, H. S. 2011. Building information modeling (BIM): benefits, risks and challenges [online], McWhorter School of Building Science, Auburn [cited 9 February 2012]. Available from Internet: http://ascpro.ascweb.org/chair/paper/CPGT182002008. pdf
Bauer, U.; Polthier, K. 2009. Generating parametric models of tubes from laser scans, Computer-Aided Design 41(10): 719-729. http://dx.doi.org/10.1016/j.cad.2009.01.002

Boehler, W.; Marbs, A. 2003. Investigating laserscanner accuracy, in Proc. of the 19th CIPA Symposium, 30 September-4 October, 2003, Antalya, Turkey 19 p.

Boehler, W.; Marbs, A. 2004. 3D scanning and photogrammetry for heritage recording: a comparison, in Proc. of the 12th International Conference on Geoinformatics, 7-8 June, 2004, Gävle, Sweden, 291-298.

Bosché, F. 2010. Automated recognition of 3D CAD model objects in laser scans and calculation of as-built dimensions for dimensional compliance control in construction, Advanced Engineering Informatics 24(1): 107-118. http://dx.doi.org/10.1016/j.aei.2009.08.006

Cheng, M.-Y.; Tsai, H.-C.; Lien, L.-C.; Kuo, C.-H. 2008. GIS-based restoration system for historic timber buildings using RFID technology, Journal of Civil Engineering and Management 14(4): 227-234. http://dx.doi.org/10.3846/1392-3730.2008.14.21

CSA. 2005. Parametric modelling in AutoCAD ${ }^{\circledR}-$ almost [online], The CSA Newsletter 17(3) [cited 12 September 2012]. Available from Internet: http://csanet.org/newsletter/winter05/nlw0506.html

Donath, D.; Thurow, T. 2007. Integrated architectural surveying and planning: methods and tools for recording and adjusting building survey data, Automation in Construction 16(1): 19-27. http://dx.doi.org/10.1016/j.autcon.2005.10.012

Eastman, T. S. L. 2008. BIM handbook: a guide to building information modeling for owners, managers, architects, engineers, contractors and fabricators. Hoboken, NJ: John Wiley and Sons, Ltd. 504 p.

Graphisoft. 2012. Graphisoft BIMx [online], [cited 12 September 2012]. Available from Internet: http://www.graphisoft.com/products/bim-explorer

Haala, N.; Kada, M. 2010. An update on automatic 3D building reconstruction, ISPRS Journal of Photogrammetry and Remote Sensing 65(6): 570-580. http://dx.doi.org/10.1016/j.isprsjprs.2010.09.006

Jiang, R.; Jáuregui, D. V.; White, K. R. 2008. Close-range photogrammetry applications in bridge measurement: literature review, Measurement 41(8): 823-834. http://dx.doi.org/10.1016/j.measurement.2007.12.005

Larsen, K. E.; Lattke, F.; Ott, S.; Winter, S. 2011. Surveying and digital workflow in energy performance retrofit projects using prefabricated elements, Automation in Construction 20(8): 999-1011. http://dx.doi.org/10.1016/j.autcon.2011.04.001

Leica Geosystems AG. 2012a. Leica ScanStation C10 datasheet [online], [cited 15 May 2012]. Available from Internet:

http://hds.leica-geosystems.com/downloads123/hds/hds/ ScanStation $\% 20 \mathrm{C} 10 /$ brochures-datasheet/Leica_ScanSt ation_C10_DS_en.pdf

Leica Geosystems AG. 2012b. Leica TDRA6000 produced inspection certificate M. Article no: 576373. Serial no: 362996.

Lerma, J. L.; Navarro, S.; Cabrelles, M.; Villaverde, V. 2010. Terrestrial laser scanning and close range photogram- 
metry for 3D archaeological documentation: the Upper Palaeolithic cave of Parpalló as a case study, Journal of Archaeological Science 37(3): 499-507. http://dx.doi.org/10.1016/j.jas.2009.10.011

Mechelke, K.; Kersten, T. P.; Lindstaedt, M. 2007. Comparative investigations into the accuracy behaviour of the new generation of terrestrial laser scanning systems [online], HafenCity University Hamburg, Hamburg [cited 14 September 2012]. Available from Internet: https://www.hcu-hamburg.de/fileadmin/documents/Ge omatik/Labor_Photo/publik/o3d2007_mechelke_et_al. pdf

Mensi. 2012. Technical specifications [online], [cited 24 August 2012]. Available from Internet: http://mensi.free.fr/english/specsoi.htm

Mill, T.; Ellmann, A.; Uueküla, K.; Joala, V. 2011. Road surface surveying using terrestrial laser scanner and total station technologies, in Proc. of the 8th International Conference Environmental Engineering, 19-20 May, 2011, Vilnius, Lithuania, 1142-1147.

Muskett, J. 1995. Site surveying. 2nd ed. Hoboken, NJ: Blackwell Science Publications. 432 p.

Ordóñez, C.; Martínez, J.; Arias, P.; Armesto, J. 2010. Measuring building façades with a low-cost closerange photogrammetry system, Automation in Construction 19(6): 742-749.

http://dx.doi.org/10.1016/j.autcon.2010.03.002

Rajala, M.; Penttilä, H. 2006. Testing 3D building modelling framework in building renovation [online], Helsinki University of Technology, Helsinki [cited 1 October 2012]. Available from Internet:

http://www.mittaviiva.fi/hannu/studies/2006_rajal_pentt ila.pdf
Riegl Laser Measurement Systems GmbH. 2011. Riegl $V Z^{\circledR}-4000$ - datasheet [online], [cited 5 June 2012]. Available from Internet: http://www.riegl.com/uploads/tx_pxpriegldownloads/10 DataSheet_VZ-4000_27-10-2011_PRELIMINARY.pdf

Schulz, T.; Ingesand, H. 2004. Terrestrial laser scanning investigations and applications for high precision scanning, in Proc. of the FIG Working Week, 22-27 May, 2004, Athens, Greece. 15 p.

Tang, P.; Akinci, B. 2012. Formalization of workflows for extracting bridge surveying goals from laser-scanned data, Automation in Construction 22: 306-319. http://dx.doi.org/10.1016/j.autcon.2011.09.006

Tse, T. K.; Wong, K. A.; Wong, K. F. 2005. The utilisation of building information models in $3 \mathrm{D}$ modelling: a study of data interfacing and adoption barriers, Journal of Information Technology in Construction, Special Issue From 3D to nD modelling 10: 85-110.

US Army Corps of Engineers. 2007. Engineering and design - control and topographic surveying [online], The Army Corps of Engineers [cited 15 October 2012]. Available from Internet:

http://publications.usace.army.mil/publications/eng-ma nuals/EM_1110-1-1005_sec/EM_1110-1-1005_Sections/ c-8.pdf

Weygant, R. S. 2011. BIM content development: standards, strategies, and best practices. Hoboken, NJ: John Wiley and Sons Ltd. 464 p.

Zoller + Fröhlich GmbH. 2012. Z +F IMAGER ${ }^{\circledR} 5010-$ datasheet [online], [cited 3 August 2012]. Available from Internet:

http://www.zf-laser.com/Brochure_IMAGER_5010.pdf

Tarvo MILL. Lecturer, MSc, the Chair of Construction Geodesy, Faculty of Construction, Tallinna Tehnikakõrgkool/University of Applied Sciences. Currently pursuing postgraduate studies towards PhD degree in Civil Engineering (Geodesy) at the TUT. Research interests: terrestrial laser scanning, engineering geodesy, building information modelling, maintenance of buildings, management of construction and built environment.

Aivars ALT. Associate Professor of Construction Management, MSc, Department of Civil Engineering, Faculty of Construction, Tallinna Tehnikakõrgkool/University of Applied Sciences. Research interests: construction management and management of built environment, building information modelling, classification of data in construction.

Roode LIIAS. Professor of Facilities Management, PhD, Department of Building Production, Dean of the Faculty of Civil Engineering, Tallinn University of Technology. Research interests: maintenance of buildings, management of construction and built environment, incl. dwellings. He has published about 90 different research papers, 7 textbooks and hand-books, and has also been the author or co-author of several National Standards on maintenance and facilities management. He has been the project manager of several national and international projects. 